\title{
The novel use of coblation whilst undertaking a challenging tracheostomy in a patient with anaplastic thyroid cancer
}

\author{
Ramkishan Balakumar*, Bhavesh Patel and Showkat Mirza \\ Sheffield Teaching Hospitals NHS Trust, Sheffield, UK
}

\begin{abstract}
Introduction: Coblation is a relatively new technique where tissue is ablated using radiofrequency energy. It has increasing applications in benign and malignant head and neck tumours.

Case report: We present the case of a 63-year-old man with an anaplastic spindle cell thyroid carcinoma, presenting to the on-call ENT team with acute stridor. A recent MRI scan showed a $7 \mathrm{~cm}$ mass invading through the lateral wall of the trachea and extending superiorly into the supraglottic larynx. The history suggested previous radiotherapy treatment. A tracheostomy under local anaesthesia was performed. The tumour was large, hard and displacing the trachea and therefore coblation was utilised for this challenging case.
\end{abstract}

Conclusion: The use of coblation was valuable in this setting as it allowed tumour debulking with haemostatic control over the thyroid cartilage and trachea. We report the first case, as far as we are aware, of the use of coblation in a surgical tracheostomy.

\section{Introduction}

Radiofrequency coblation technology is a relatively new surgical tool to allow haemostasis and dissection. Although it was first introduced for orthopaedic surgery [1], more recently coblation has been used in head and neck surgery for various procedures including adenotonsillectomy, inferior turbinate reduction, soft tissue volume reduction for sleep apnoea and resection of head and neck malignancies $[2,3]$.

It is an example of high-frequency electrosurgery, which involves passing radiofrequency energy through a conductive medium, such as isotonic sodium chloride solution. The conductive medium produces a plasma field, which allows sufficient energy to break organic molecular bonds through its energetic charge carrying ions. This technique achieves a low-temperature molecular disintegration of the tissue with temperatures between 40 to 70 degrees compared to the much higher temperatures with electrosurgery; these results in less post-operative pain [4]. The technique is usually used through a bipolar device, known as a coblation wand to remove the target tissue with minimal damage to surrounding tissues. Many coblation devices are also designed to stop bleeding and coagulate bleeding vessels [1].

The hospital episode statistics states that between 2014 and 2015 there were 2,314 procedures coded as 'Coblation of organ Non-organconfined' [5]. We report the first case, as far as we are aware, of the use of coblation in a surgical tracheostomy.

\section{Case report}

A 63 year old man from Slovakia presented to the Endocrinology surgeons with a thyroid mass. A CT scan of the neck showed a large mass arising from the left lobe of the thyroid gland invading into the airway and into the soft tissues of the paravertebral tissues. The trachea was displaced to the right side. An MRI scan of the neck
(Figure 1) showed a large necrotic mass in the lower neck measuring approximately $7 \mathrm{~cm}$ in its greatest diameter with invasion through the lateral wall of the trachea and probably the anterior wall as well as extension superiorly to the level of the supraglottic larynx. A biopsy was performed and was in keeping with an anaplastic spindle cell thyroid carcinoma. He had some difficulty breathing which progressed to acute stridor and was subsequently transferred to the on call ENT team. This was initially managed medically with adrenaline nebulisers and intravenous dexamethasone.

The patient was a poor historian but there was a history suggestive of previous radiotherapy treatment in Slovakia. A tracheostomy under local anaesthesia was required to secure the airway. This was undertaken

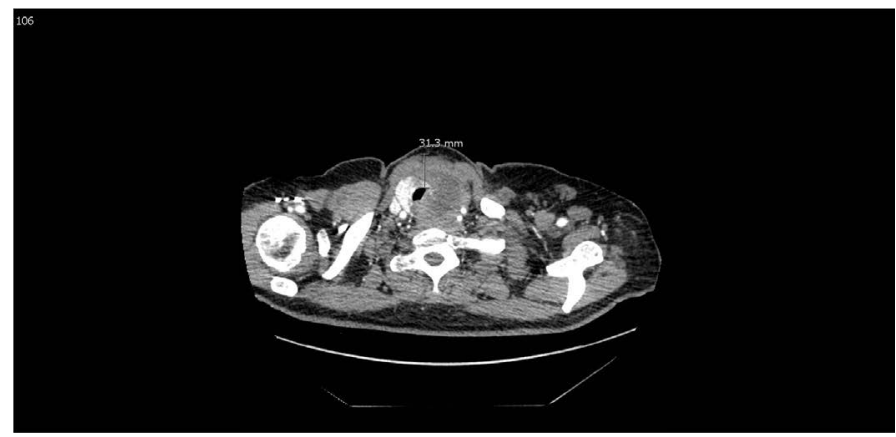

Figure 1. Axial View of MRI neck showing tumour invading the trachea.

Correspondence to: Ramkishan Balakumar, Sheffield Teaching Hospitals NHS Trust, Sheffield, UK; Email: rambala86@doctors.org.uk

Key words: coblation, head and neck tumour, anaplastic, thyroid, tracheostomy

Received: September 10, 2016; Accepted: October 13, 2016; Published: October 17,2016 
in theatre on the emergency list by an ENT consultant. A horizontal skin incision was made. As soon as the strap muscles were retracted a large hard mass of tumour extending from the thyroid cartilage to the suprasternal notch was seen. In general, midline dissection would locate the trachea but in this case the trachea was significantly displaced to the right side by the tumour. The planes were difficult to identify due to the carcinoma distorting the anatomy making differentiation of tumour and thyroid cartilage very difficult. Therefore, the novel use of a coblation wand (Smith \& Nephew, Coblation setting 7, bipolar setting 3) was employed to help debulk the tumour and provide haemostasic control simultaneously over the thyroid cartilage [6]. Tumour was removed to reveal the thyroid cartilage and then tumour removal progressed inferiorly to identify the cricoid cartilage and then eventually the trachea. The coblation achieved enough tumour removal to provide a window of access to enable the tracheostomy tube to be placed between the $2^{\text {nd }}$ and $3^{\text {rd }}$ tracheal rings. The patient was initially observed in the high dependency unit post-operatively, and then returned to the ward the next day after recovery. He remained in the ward with no further issues and was discharged home once he and his family received adequate tracheostomy care training. The case was discussed in the Head \& Neck multidisciplinary meeting and a package of palliative care was instigated.

\section{Discussion}

Anaplastic thyroid carcinoma, though rare, is one of the most aggressive cancers known to affect humans [7]. More than $50 \%$ of patients have metastatic disease on presentation with the lung, bone and brain being the common sites. It accounts for $1.6 \%$ of all thyroid cancer and has a very poor prognosis with a median survival rate of 4 to 12 months. The disease is categorised into three types; spindle cell; giant cell and squamoid, although the prognosis is the same. The mean age of diagnosis is 55 to 65 years and usually presents with a rapidly enlarging mass. Other symptoms associated with mechanical compression, such as stridor, dysphonia, dyspnoea, dysphagia and neck pain are also present. This can be the case for patients where structures such as the oesophagus and trachea can be affected in 44 and $46 \%$ of the time respectively [8]. A tracheostomy can relieve airway distress and prolong life, although prolongation of life can result in further suffering from the advanced disease. A tracheostomy is indicated for those with impending airway loss $[9,10]$, as was the case for our patient.

There are few papers in the literature regarding the use of coblation for head and neck malignancy. A database search of PubMed, Embase, Google Scholar and Cochrane Library with the MeSH terms: 'Coblation; Head and neck tumour; Anaplastic, Thyroid, Tracheostomy' was undertaken to identify any potential case studies that have reported such cases. The literature search showed various cases including earlystage glottic cancer [11], laryngeal papillomas [12], mucosal squamous cell carcinoma of the head and neck [3] and thyroid adenoma [13] with the use of coblation. However, there was nothing in the literature that alluded to the use of coblation for tracheostomy, making this the first case to use this novel technique.

The open surgical tracheostomy became an established procedure in the $19^{\text {th }}$ century for upper airway obstruction secondary to foreign body and infections. The surgical principles were defined by Chevalier Jackson, which are still in existence today. These include a long incision, good exposure, division of the isthmus, and avoidance of the first and second tracheal rings [14]. The conventional surgical tracheostomy uses a combination of cold dissection and electrocautery to gain haemostasis. However, coblation allows both ablation of tumour and haemostasis to be undertaken simultaneously. Animal studies have also shown further advantages, including faster wound healing, less extent of inflammation and granulation tissue production, and less tissue injury as compared to electrocautery [15]. The conventional approach in this scenario would have proven very difficult in identifying the planes and controlling bleeding whilst debulking the tumour. Therefore, coblation allows more effective technique in this challenging case.

\section{Summary}

- The case reports a 63-year-old gentleman with anaplastic spindle cell thyroid carcinoma presenting with stridor

- The tumour had invaded through the lateral wall of the trachea and extended superiorly into the supraglottic larynx

- A tracheostomy under local anaesthesia was performed which was challenging due to the tumour distorting the anatomy and displacing the trachea to the right

- Coblation was therefore utilised, allowing haemostatic control whilst tumour debulking to reveal the trachea

This is the first surgical tracheostomy performed using coblation to our best of our knowledge.

\section{References}

1. Burton MJ, Doree C (2009) Coblation versus other surgical techniques for tonsillectomy. Cochrane Database Syst Rev. CD004619. [Crossref]

2. Shapiro NL, Bhattacharyya N (2007) Cold dissection versus coblation-assisted adenotonsillectomy in children. Laryngoscope 117: 406-410. [Crossref]

3. Carney AS, Timms MS, Marnane CN, Krishnan S, Rees G, et al. (2008) Radiofrequency coblation for the resection of head and neck malignancies. Otolaryngol Head Neck Surg 138: 81-85. [Crossref]

4. Chawla S, Carney AS (2009) Organ preservation surgery for laryngeal cancer. Head Neck Oncol 1: 12. [Crossref]

5. HSCIC (2015) Hospital Episode Statistics Admitted Patient Care, England 2014-2015.

6. Smith \& Nephew (2016) COBLATION-Plasma Technology.

7. Pacini F, Castagna MG, Brilli L, Pentheroudakis G, ESMO Guidelines Working Group (2012) Thyroid cancer: ESMO clinical practice guidelines for diagnosis, treatment and follow-up. Ann Oncol. 21: v214-219. [Crossref]

8. Are C, Shaha AR (2006) Anaplastic thyroid carcinoma: biology, pathogenesis, prognostic factors, and treatment approaches. Ann Surg Oncol. 13: 453-464. [Crossref]

9. Smallridge RC, Ain KB, Asa SL, Bible KC, Brierley JD, et al. (2012) American Thyroid Association guidelines for management of patients with anaplastic thyroid cancer. Thyroid. 22: 1104-1139. [Crossref]

10. Perros P, Boelaert K, Colley S, Evans C, Evans RM, et al. (2014) Guidelines for the management of thyroid cancer. Clin Endocrinol (Oxf) 81 Suppl 1: 1-122. [Crossref]

11. Cheng L, Liu B, Tian A, Ming H (2013) [Treatment of early-stage glottic cancer with radiofrequency coblation]. Lin Chung Er Bi Yan Hou Tou Jing Wai Ke Za Zhi 27: 153154. [Crossref]

12. Timms MS, Bruce IA, Patel NK (2007) Radiofrequency ablation (coblation): a promising new technique for laryngeal papillomata. J Laryngol Otol. 121: 28-30. [Crossref]

13. Wang ZL, Yang G, Su JF (2012) Curative effect of coblation thyroidectomy on thyroid adenoma. Chinese Journal of Otorhinolaryngology-Skull Base Surgery. 1: 011.

14. Dulguerov P, Gysin C, Perneger TV, Chevrolet JC (1999) Percutaneous or surgical tracheostomy: a meta-analysis. Crit Care Med 27: 1617-1625. [Crossref]

15. Glade RS, Pearson SE, Zalzal GH, Choi SS (2006) Coblation adenotonsillectomy: an improvement over electrocautery technique? Otolaryngol Head Neck Surg 134: 852855. [Crossref]

Copyright: (C2016 Balakumar R. This is an open-access article distributed under the terms of the Creative Commons Attribution License, which permits unrestricted use, distribution, and reproduction in any medium, provided the original author and source are credited. 